\title{
The Role of the Unfolded Protein Response in the Heart
}

\author{
Christopher C. Glembotski \\ The SDSU Heart Institute and the Department of Biology, San Diego State University, San Diego, \\ CA 92182
}

\begin{abstract}
The misfolding of nascent proteins, or the unfolding of proteins after synthesis is complete, can occur in response to numerous environmental stresses, or as a result of mutations that de-stabilize protein structure. Cells have developed elaborate protein quality control systems that recognize improperly folded proteins and either refold them, or facilitate their degradation. One such quality control system is the unfolded protein response, or the UPR. The UPR is a highly conserved signal transduction system that is activated when cells are subjected to conditions that alter the endoplasmic reticulum (ER) in ways that impair the folding of nascent proteins in this organelle. Recent observations indicate that in the heart, the UPR is activated during acute stresses, including ischemia/reperfusion, as well as upon longer-term stresses that lead to cardiac hypertrophy and heart failure. Moreover, certain aspects of the UPR are activated during, and are required for proper heart development. This review summarizes recent studies of the UPR in the heart, focusing on the possible roles of the UPR in contributing to, or protecting from ischemia/reperfusion damage.
\end{abstract}

\section{Introduction}

The function of most proteins depends on their 3-dimensional conformation, which requires correct folding. The bulk of cellular protein synthesis takes place on cytosolic free ribosomes. However, depending on the cell type, up to $35 \%$ of protein synthesis is in the rough endoplasmic reticulum (ER), which is where all secreted proteins, as well as proteins that are targeted to membranes and organelles are synthesized [1]. Under optimal conditions, numerous chaperones and other proteins and factors, ensure efficient nascent protein folding; however, perturbation of folding machinery components decreases protein folding efficiency. Initially, the accumulation of misfolded proteins triggers biochemical events designed to augment protein folding capacity. However, the continued accumulation of terminally misfolded proteins leads to their degradation by a well studied protein quality control system, involving recognition, ubiquitination and degradation by proteasomes and, eventually, to cell death. Protein quality control systems are located in several cell locations, including the cytosol and the ER; several reviews of the cytosolic protein quality control system in the heart have recently appeared [2,3]. Accordingly, this review focuses on ER-associated protein quality control system, also known as the unfolded protein response (UPR).

(C) 2007 Elsevier Ltd. All rights reserved.

(619) 594-2959, (619) 594-5676 FAX, e-mail: cglembotski@ sciences.sdsu.edu.

Publisher's Disclaimer: This is a PDF file of an unedited manuscript that has been accepted for publication. As a service to our customers we are providing this early version of the manuscript. The manuscript will undergo copyediting, typesetting, and review of the resulting proof before it is published in its final citable form. Please note that during the production process errors may be discovered which could affect the content, and all legal disclaimers that apply to the journal pertain. 


\section{The Unfolded Protein Response}

The unfolded protein response (UPR) is a conserved signal transduction system that is activated by stresses that impact the efficiency of protein folding in the rough ER [4-7]. Optimal protein folding in the ER depends on maintaining the the proper balance of numerous components in the ER that contribute to folding of proteins during synthesis. For example, the correct ER redox status is required for protein disulfide bond formation, which is an oxygen-requiring process. Also, maintenance of suitable levels of protein glycosylation substrates, as well as sufficient glycosylation enzymatic machinery, are required, since most proteins made in the ER are glycosylated. Finally, ER calcium and ER resident chaperones must be present at the levels that facilitate optimal folding of nascent ER proteins.

Experimentally, the ER environment can be perturbed by substances, such as dithiothrietol, thapsigargin, or tunicamycin, which alter redox status, calcium levels and protein glycosylation in the ER, respectively [4,8-10]. When cells are treated with one of these compounds, or if they are starved of glucose and oxygen, the latter of which mimics ischemia, ER protein folding is impaired, and the accumulation of mis-folded, dysfunctional proteins signals the initiation of ER stress [11].

ER stress is initially sensed by the 3 ER-transmembrane proteins, protein kinase R-like ER kinase (PERK) [12], activating transcription factor 6 (ATF6) [13,14] and inositol-requiring enzyme-1 (IRE-1) [15,16], which serve as the primary proximal effectors of the UPR.

Numerous studies in yeast, as well as mammalian cell lines and a few tissues have contributed considerably to our understanding of the mechanisms of action of each of these effectors.

Several excellent reviews report on the results of these studies [17]; accordingly, the following is a summary of the mechanisms by which these effectors sense ER stress and mediate downstream signals.

When ER protein folding is functioning efficiently, the ER luminal domains of PERK, ATF6 and IRE-1 are bound to the abundant ER-resident chaperone, glucose-regulated protein 78 (GRP78). Under these conditions, these proximal effectors of the UPR are inactive (Fig. 1A). However, when ER protein folding is disrupted, and misfolded proteins begin to accumulate, GRP78 translocates from PERK, IRE-1 and ATF6 to the misfolded proteins in an apparent effort to aid in folding [18-22]. This translocation of GRP78 leads to the activation of all 3 proximal effectors of the UPR (Fig. 1B), and is considered one of the earliest signs of ER stress. Once activated, the 3 proximal effectors of the UPR mediate the downstream, or distal effects of ER stress.

\section{Proximal Effectors of ER Stress (PERK, IRE-1 and ATF6) PERK}

PERK is a transmembrane ER protein; upon ER stress, and the relocation of GRP78 from the luminal domain of PERK to misfolded proteins, and the subsequent homodimerization of PERK, lead to trans-autophosphorylation, much like activated growth factor receptors. This autophosphorylation activates PERK, further, which phosphorylates the ribosomal protein, eIF2 $\alpha$. Phosphorylation of eIF $2 \alpha$ decreases its efficiency as an initiator of translation, which leads to decreased translation of most cellular mRNAs (Fig. 1C; translation arrest) [18]. This translational arrest, which is transient, reduces the protein synthesis load in the ER, facilitating recovery of ER homeostasis and the re-establishment of efficient ER protein folding [23]. Although most mRNAs are inefficiently translated upon PERK activation, paradoxically, the mRNA that encodes activator of transcription factor 4 (ATF4) is translated more efficiently when eIF $2 \alpha$ is phosphorylated. This leads to increased levels of ATF4, which serves important 
roles as a transcriptional inducer of a certain ER stress response genes, such as those that encode amino acid transporters, which assist in recovery from the stress (Fig. 1C; ATF4).

IRE-1

Much like PERK, IRE-1 is an ER transmembrane protein, which, upon ER stress, forms homodimers which facilitate trans-autophosphorylation. However, in contrast to PERK, upon ER stress, IRE-1 exhibits a novel endoribonuclease activity, which splices the mRNA that encodes active $x$-box binding protein-1, (XBP1). This unusual splicing event, which takes place in the cytosol, generates a transcript with a new open reading frame that encodes the expression of an active form of XBP1, a basic leucine-zipper (bZip) transcription factor that induces numerous ER stress response genes (Fig. 1C; IRE1 XBP1) [21,24].

ATF6

Like PERK and IRE-1, ATF6 is an ER transmembrane protein that also exists as a dimer in association with GRP78 under non-stressed conditions. In further comparison, upon ER stress GRP78 dissociates from the ER-luminal domain of ATF6. However, in contrast to the other two effectors, which remain associated with the ER, ATF6 re-locates to the Golgi, where two proteases, site- 1 and site- 2 proteases, cleave it in, or near the transmembrane region. After these cleavage events, the cytosolic region of ATF6, which has several putative nuclear localization signals, translocates to the nucleus where it can form homodimers or heterodimers with a small group of b-Zip transcription factors, which includes XBP1, leading to the transcriptional regulation of ER stress response genes (Fig. 1C; ATF6) [25,26]. A second isoform of ATF6, ATF6 $\beta$ [27], as well as other ATF6-related proteins, such as Oasis [28], Luman [29,30], CREB4 [31], CREB-H [31] and BBF2H7 [32], have since been discovered. Like ATF6, all of these isoforms are ER trans-membrane proteins that are cleaved and translocate to the nucleus upon ER stress. Moreover, in theory, each has the ability to dimerize with other members of this b-Zip transcription factor family. Although the exact roles of these ATF6 isoforms are not completely known, it appears as though ATF6 $\beta$ has less ability to induce ER stress response genes than ATF6 [33], and may even serve as an inhibitor of ATF6 [34, 35]. Additionally, some of the other isoforms exhibit tissue-restricted expression patterns, implying that they may contribute to mediating ER stress in a cell type specific manner.

\section{Distal Effectors of the UPR}

Many of the XBP1 and ATF6 inducible genes that have been characterized to date can be induced by either transcription factor. Thus, there is a great deal of redundancy between these two UPR pathways, although the reasons for this redundancy are not yet clear. However, the recent development of ATF6 knock out mice has clarified the existence of numerous ER stress response genes that are dependent upon ATF6 for maximal induction during ER stress [33]. Most of the genes induced by XBP1 and/or ATF6 encode mRNAs with structural features allowing them to escape PERK-mediated translational arrest. Genes induced upon acute ER stress encode proteins that improve the folding of nascent proteins in the ER lumen and facilitate the degradation of dysfunctional misfolded proteins. The degradation of terminally misfolded ER proteins is performed by ER associated protein degradation, or ERAD. ERAD is a complex process involving the recognition of misfolded ER proteins, followed by the retrotranslocation of these proteins across the ER membrane to the cytosolic face of the ER. Protein degradation machinery, located on the cytosolic face of the ER, is dedicated to the ubiquitination and proteasome-mediated degradation of terminally misfolded ER proteins [36-38]. Together, the ER-luminal and ERAD-associated proteins function to resolve the ER stress, fostering the recovery of efficient ER protein folding and cell survival (Fig. 1D; Survival/Recovery). 
If the UPR signals activated in the early phases of ER stress are not sufficient to resolve the stress, continued activation of the proximal effectors leads to the up-regulation of a different collection of UPR-inducible proteins (Fig. 1D; Apoptosis), as well as the activation of other signaling pathways, that combine to promote cell death (Fig. 1C; JNK and caspase-12) [39, 40]. ER stress can also promote cell death in collaboration with the mitochondrial apoptosis pathway. For example, ER stress causes the release of cytochrome c [41]. Moreover, the proapoptotic Bcl-2 family members, Bax and Bak, associate with the ER, where they activate IRE1, thus linking mitochondrial and ER mediated apoptotic pathways [42]. Accordingly, the strength and duration of the ER stress contribute to determining the ultimate role of the UPR as either a survival or a death oriented signaling pathway.

One of the most thoroughly studied ER stress response genes is GRP78, which is also expressed in many cell types under non-stressed conditions, but upon activation of the UPR, is induced further. The GRP78 promoter has ER stress response elements (ERSEs) that bind XBP1 or ATF6, which is required for transcriptional induction during ER stress [14,43,44]. Like GRP78, most of the other ER stress response genes that have been characterized also have ERSEs [45], indicating that this transcriptional induction mechanism is highly conserved amongst genes that are induced during the UPR. Increased expression of GRP78 during the UPR enhances the protein folding capacity in the ER; if the load of misfolded proteins is reduced via this mechanism, by binding to the proximal effectors of ER stress, GRP78 contributes to inactivating the UPR, signaling resolution of the stress. Moreover, it was shown that during long-term ER stress, GRP78 redistributes from the ER to other locations, including the cytosol, where it can bind to and prevent the release of caspase- 12 from the ER, thus inhibiting the apoptotic phase of the UPR [46].

\section{Ischemia as an Activator of the UPR}

Although studies employing chemicals to induce ER stress in cultured cells and, in a few cases, in vivo, have been useful in delineating the molecular details of the UPR, such conditions are relatively extreme, and are not likely to represent physiologically meaningful stresses. In contrast, the lack of oxygen and nutrients that take place during ischemia are known to affect the ER environment in ways predicted to activate the UPR. For example, glucose deprivation was one of the first maneuvers shown to activate the UPR, probably by impeding protein glycosylation in the ER, thus mimicking the effects of tunicamcyin $[9,10]$. GRP78 was named a glucose-response protein based on its induction in cultured cells subjected to glucose starvation $[47,48]$. Additionally, the machinery responsible for disulfide bond formation in the ER requires molecular oxygen for proper function [49].

Some of the earliest studies on the effects of ischemia/reperfusion on the UPR were carried out in the brain. For example, it was shown that in ischemic rabbit brain, several features of the UPR were activated, including PERK, eIF2 $\square$ phosphorylation, translational arrest and XBP1 mRNA splicing [50]. Moreover, ischemic pre-conditioning in the brain has been shown to induce GRP78 and to protect from further ischemic damage [51]. Gene array studies have shown that transient cerebral artery occlusion increases the expression of numerous UPRdependent genes in the brain [52]. In addition to brain, numerous studies of the UPR have been carried out in tumors and cancer cell lines. For example, the UPR was shown to be activated in ischemic regions of tumors and in cultured tumor cells subjected to hypoxia; in both contexts, UPR activation was protective [53]. As a result of numerous studies in the tumor cell context, it has been suggested that the UPR provides a selective advantage to some aggressively growing solid tumors, where the rate of growth sometimes surpasses neo-angiogenesis, leading to ischemia and activation of the UPR [54]. In this context, since the UPR protects the growing tumor, and has been shown to contribute to malignant progression, the therapeutic strategy has been to inhibit the UPR in order to moderate tumor growth [55]. 
The demonstration that the UPR is activated in hypoxic tumor cells and tissue, as well as is the ischemic brain, prompted studies of whether the UPR is activated by ischemic in the heart, or by simulated ischemia in cultured cardiac myocytes. GRP78, was shown to increase in mouse hearts subjected to ex vivo ischemia/reperfusion, as well as in surviving cardiac myocytes that border the infarct zone in a mouse model of in vivo myocardial infarction [56]. Another study showed that GRP78 was induced and XBP1 was activated in hearts subjected to ischemia/reperfusion in vivo [57]. Transgenic overexpression of monocyte chemoattractant protein-1 (MCP-1) in mouse hearts was shown to induce ischemic heart disease and increase the expression of numerous ER stress response genes, including GRP78 [58]. Also, a number of ER stress response genes, including protein disulfide isomerase, were shown to be induced in the peri-infarct zone in a mouse model of myocardial infarction [59]. Several studies have shown that simulating ischemia or ischemia/reperufsion in cultured neonatal rat or adult mouse ventricular myocytes, or in the HL-1 atrial myocyte cell line, activates XBP1 and increases the expression of GRP78, and other genetic markers of the UPR [56,57,59-61].

Thus, ischemia and ischemia/reperfusion activate numerous features of the UPR in cardiac myocytes in vivo and in vitro; however, in contrast to studies in tumor cells and in the brain, where ER stress has been shown to be protective, it is less clear what function the UPR serves in the cardiac context. Some studies support protective roles for the UPR; for example, preactivation of ATF6 in the hearts of transgenic mice was shown to protect the heart from ischemia/reperfusion damage [62], suggesting that under these conditions, genes induced by the ATF6 branch of the UPR served protective functions. Also, adenoviral-mediated overexpression of the ER stress response gene for protein disulfide isomerase decreased the size of infarcts in mouse hearts subjected to in vivo coronary artery ligation [59]. In other studies, it was shown that upregulation of GRP78 during ischemic pre-conditioning is responsible for protecting cultured cardiac myocytes from further ischemic injury [63], and that preinducing ER stress response genes with tunicamycin protects H9c2 cardiomyocytes from death induced by simulated ischemia/reperfusion [64]. It has also been shown that overexpression of the ER stress response gene, GRP94, protects cultured cardiac myocytes from death in response to simulated ischemia [65]. Taken together, these studies suggest that when the UPR is activated in the heart during ischemia, or ischemia/reperfusion, it may contribute to a protective stress response mounted by cardiac myocytes.

In contrast to the studies cited above, other results support the possibility that the UPR may contribute to ischemia/reperfusion damage in the heart. In cultured cardiac myocytes, it was shown that AMP kinase and ER stress were both activated during simulated ischemia, and that in this context, by inhibiting ER stress, AMP kinase protected the cells from hypoxic injury [60]. ER stress has been shown to activate autophagy-mediated cell death cardiac myocytes subjected to simulated ischemia/reperfusion [66]. Additionally, in cultured cardiac myocytes, ER stress leads to the activation of PKC delta, but that inhibiting delta PKC activation decreases ER stress-mediated apoptosis [57]. Overexpression of the ER stress response gene, p53upregulated modulator of apoptosis (PUMA), increased apoptosis in cultured cardiomyocytes subjected to activation of the UPR [67], and targeted deletion of PUMA in mouse hearts was associated with reduced cardiomyoycte death upon ex vivo ischemia/reperfusion [68].

Although the reasons underlying the seemingly paradoxical results described above are not known, it is possible that like some other signaling pathways, the UPR can mediate both protective and damaging effects in the heart, depending upon the context. In support of this possibility is a study which showed that in cultured cardiac myocytes, simulated ischemia activated protective aspects of the UPR at early times, but at later times, apoptotic features of the UPR were dominant [61]. This finding is consistent with general views that during the initial phases of ER stress, the UPR mediates induction and activation of protective genes and proteins, but upon continued ER stress, pro-apoptotic machinery is activated. Although the 
mechanistic details of such a dual function for the UPR are still being worked out, one possibility is that ATF6, PERK and IRE-1 may be activated to different extents, depending upon the strength and nature of the ER stress, and that some effectors, e.g. ATF6, might mediate activation of mostly protective genes [33,62], while others, e.g. PERK, may induce a greater number of pro-apoptotic genes. In a study designed to examine this possibility, it was shown that in cultured fibroblasts, even mild ER stress activates the 3 proximal effectors of the UPR to similar extents, which argues against selective activation of ER stress response effectors as a mechanism [69]. In the same study, it was shown that during mild ER stress, survival is favored due to the intrinsic instabilities of mRNAs and proteins that promote apoptosis compared to those that facilitate protein folding and adaptation. Thus, it is possible that in the heart, brief ischemic stress leads to a change in the UPR-regulated proteome that fosters protection, while more prolonged ischemia alters the proteome in ways that contribute to damage.

\section{Future Directions}

This review has focused on roles for the UPR in the ischemic myocardium, which are just beginning to be appreciated. In this context, many potentially important studies concerning the function of the UPR in the heart are yet to be carried out. For example, it will be important to determine what parameters dictate when the UPR fosters protection and when in contributes to damage in the ischemic heart. This information, coupled with a more complete understanding of the levels and functions of genes, and ultimately, UPR-regulated proteins, during ischemic stress, will be required in order to fully appreciate the impact of ER stress on myocardial function in the ischemic heart. It will also be important to determine how the UPR interacts with, and is influenced by the numerous other signaling pathways known to be activated in the ischemic heart, including hypoxia-inducible factor-1, AMP kinase, nitric oxide synthase, nuclear factor kappa B, as well as the mitogen activated protein kinase and protein kinase $\mathrm{C}$ families. Finally, there is evidence that in addition to ischemia, the UPR is activated in the heart under other conditions, including hypertrophy and heart failure [58,70,71]. Moreover, the UPR appears to be important for cardiac development [72,73], as shown by the finding that the targeted deletion of the XBP1 in mice leads to embryonic lethality due to incomplete heart development [74]. Thus, it is apparent that the ER-associated UPR protein quality control system plays important roles in the normal heart, as well as the stressed and diseased heart, underscoring the importance of future studies aimed at elucidating the roles of this intricate signaling pathway in the heart.

\section{References}

[1]. Blobel G. Protein targeting. Biosci Rep Oct;2000 20(5):303-44. [PubMed: 11332596]

[2]. Wang X, Robbins J. Heart failure and protein quality control. Circ Res Dec 8;2006 99(12):1315-28. [PubMed: 17158347]

[3]. Patterson C, Ike C, Willis PWt, Stouffer GA, Willis MS. The bitter end: the ubiquitin-proteasome system and cardiac dysfunction. Circulation Mar 20;2007 115(11):1456-63. [PubMed: 17372187]

[4]. Drummond IA, Lee AS, Resendez E Jr. Steinhardt RA. Depletion of intracellular calcium stores by calcium ionophore A23187 induces the genes for glucose-regulated proteins in hamster fibroblasts. J Biol Chem Sep 15;1987 262(26):12801-5. [PubMed: 3114264]

[5]. Lee AS. Mammalian stress response: induction of the glucose-regulated protein family. Curr Opin Cell Biol Apr;1992 4(2):267-73. [PubMed: 1599691]

[6]. Shamu CE, Cox JS, Walter P. The unfolded-protein-response pathway in yeast. Trends Cell Biol Feb;1994 4(2):56-60. [PubMed: 14731868]

[7]. McMillan DR, Gething MJ, Sambrook J. The cellular response to unfolded proteins: intercompartmental signaling. Curr Opin Biotechnol Oct;1994 5(5):540-5. [PubMed: 7765470] 
[8]. Kim YK, Lee AS. Transcriptional activation of the glucose-regulated protein genes and their heterologous fusion genes by beta-mercaptoethanol. Mol Cell Biol Aug;1987 7(8):2974-6. [PubMed: 3670303]

[9]. Kozutsumi Y, Segal M, Normington K, Gething MJ, Sambrook J. The presence of malfolded proteins in the endoplasmic reticulum signals the induction of glucose-regulated proteins. Nature Mar 31;1988 332(6163):462-4. [PubMed: 3352747]

[10]. Dorner AJ, Wasley LC, Raney P, Haugejorden S, Green M, Kaufman RJ. The stress response in Chinese hamster ovary cells. Regulation of ERp72 and protein disulfide isomerase expression and secretion. J Biol Chem Dec 15;1990 265(35):22029-34. [PubMed: 2254345]

[11]. Chang SC, Wooden SK, Nakaki T, Kim YK, Lin AY, Kung L, et al. Rat gene encoding the 78-kDa glucose-regulated protein GRP78: its regulatory sequences and the effect of protein glycosylation on its expression. Proc Natl Acad Sci U S A Feb;1987 84(3):680-4. [PubMed: 3468506]

[12]. Shi Y, Vattem KM, Sood R, An J, Liang J, Stramm L, et al. Identification and characterization of pancreatic eukaryotic initiation factor 2 alpha-subunit kinase, PEK, involved in translational control. Mol Cell Biol Dec;1998 18(12):7499-509. [PubMed: 9819435]

[13]. Zhu C, Johansen FE, Prywes R. Interaction of ATF6 and serum response factor. Mol Cell Biol Sep; 1997 17(9):4957-66. [PubMed: 9271374]

[14]. Yoshida H, Haze K, Yanagi H, Yura T, Mori K. Identification of the cis-acting endoplasmic reticulum stress response element responsible for transcriptional induction of mammalian glucoseregulated proteins. Involvement of basic leucine zipper transcription factors. J Biol Chem Dec 11;1998 273(50):33741-9. [PubMed: 9837962]

[15]. Cox JS, Shamu CE, Walter P. Transcriptional induction of genes encoding endoplasmic reticulum resident proteins requires a transmembrane protein kinase. Cell Jun 18;1993 73(6):1197-206. [PubMed: 8513503]

[16]. Mori K, Ma W, Gething MJ, Sambrook J. A transmembrane protein with a cdc2+/CDC28-related kinase activity is required for signaling from the ER to the nucleus. Cell Aug 27;1993 74(4):74356. [PubMed: 8358794]

[17]. Kohno K. How Transmembrane Proteins Sense Endoplasmic Reticulum Stress. Antioxid Redox Signal. Sep 26;2007

[18]. Bertolotti A, Zhang Y, Hendershot LM, Harding HP, Ron D. Dynamic interaction of BiP and ER stress transducers in the unfolded-protein response. Nat Cell Biol Jun;2000 2(6):326-32. [PubMed: 10854322]

[19]. Ma K, Vattem KM, Wek RC. Dimerization and release of molecular chaperone inhibition facilitate activation of eukaryotic initiation factor-2 kinase in response to endoplasmic reticulum stress. J Biol Chem May 24;2002 277(21):18728-35. [PubMed: 11907036]

[20]. Shamu CE, Walter P. Oligomerization and phosphorylation of the Ire1p kinase during intracellular signaling from the endoplasmic reticulum to the nucleus. Embo J Jun 17;1996 15(12):3028-39. [PubMed: 8670804]

[21]. Sidrauski C, Walter P. The transmembrane kinase Ire1p is a site-specific endonuclease that initiates mRNA splicing in the unfolded protein response. Cell Sep 19;1997 90(6):1031-9. [PubMed: 9323131]

[22]. Shen J, Snapp EL, Lippincott-Schwartz J, Prywes R. Stable binding of ATF6 to BiP in the endoplasmic reticulum stress response. Mol Cell Biol Feb;2005 25(3):921-32. [PubMed: 15657421]

[23]. Harding HP, Zhang Y, Ron D. Protein translation and folding are coupled by an endoplasmicreticulum-resident kinase. Nature Jan 21;1999 397(6716):271-4. [PubMed: 9930704]

[24]. Calfon M, Zeng H, Urano F, Till JH, Hubbard SR, Harding HP, et al. IRE1 couples endoplasmic reticulum load to secretory capacity by processing the XBP-1 mRNA. Nature Jan 3;2002 415(6867): 92-6. [PubMed: 11780124]

[25]. Shen J, Chen X, Hendershot L, Prywes R. ER stress regulation of ATF6 localization by dissociation of BiP/GRP78 binding and unmasking of Golgi localization signals. Dev Cell Jul;2002 3(1):99111. [PubMed: 12110171] 
[26]. Ye J, Rawson RB, Komuro R, Chen X, Dave UP, Prywes R, et al. ER stress induces cleavage of membrane-bound ATF6 by the same proteases that process SREBPs. Mol Cell Dec;2000 6(6):135564. [PubMed: 11163209]

[27]. Haze K, Okada T, Yoshida H, Yanagi H, Yura T, Negishi M, et al. Identification of the G13 (cAMPresponse-element-binding protein-related protein) gene product related to activating transcription factor 6 as a transcriptional activator of the mammalian unfolded protein response. Biochem $\mathrm{J}$ Apr 1;2001 355(Pt 1):19-28. [PubMed: 11256944]

[28]. Kondo S, Murakami T, Tatsumi K, Ogata M, Kanemoto S, Otori K, et al. OASIS, a CREB/ATFfamily member, modulates UPR signalling in astrocytes. Nat Cell Biol Feb;2005 7(2):186-94. [PubMed: 15665855]

[29]. Lu R, Yang P, O'Hare P, Misra V. Luman, a new member of the CREB/ATF family, binds to herpes simplex virus VP16-associated host cellular factor. Mol Cell Biol Sep;1997 17(9):5117-26. [PubMed: 9271389]

[30]. DenBoer LM, Hardy-Smith PW, Hogan MR, Cockram GP, Audas TE, Lu R. Luman is capable of binding and activating transcription from the unfolded protein response element. Biochem Biophys Res Commun May 27;2005 331(1):113-9. [PubMed: 15845366]

[31]. Stirling J, O'Hare P. CREB4, a transmembrane bZip transcription factor and potential new substrate for regulation and cleavage by S1P. Mol Biol Cell Jan;2006 17(1):413-26. [PubMed: 16236796]

[32]. Kondo S, Saito A, Hino S, Murakami T, Ogata M, Kanemoto S, et al. BBF2H7, a novel transmembrane bZIP transcription factor, is a new type of endoplasmic reticulum stress transducer. Mol Cell Biol Mar;2007 27(5):1716-29. [PubMed: 17178827]

[33]. Wu J, Rutkowski DT, Dubois M, Swathirajan J, Saunders T, Wang J, et al. ATF6alpha optimizes long-term endoplasmic reticulum function to protect cells from chronic stress. Dev Cell Sep;2007 13(3):351-64. [PubMed: 17765679]

[34]. Thuerauf DJ, Morrison L, Glembotski CC. Opposing roles for ATF6alpha and ATF6beta in endoplasmic reticulum stress response gene induction. J Biol Chem May 14;2004 279(20):2107884. [PubMed: 14973138]

[35]. Thuerauf DJ, Marcinko M, Belmont PJ, Glembotski CC. Effects of the isoform-specific characteristics of ATF6 alpha and ATF6 beta on endoplasmic reticulum stress response gene expression and cell viability. J Biol Chem Aug 3;2007 282(31):22865-78. [PubMed: 17522056]

[36]. Brodsky JL. The protective and destructive roles played by molecular chaperones during ERAD (endoplasmic-reticulum-associated degradation). Biochem J Jun 15;2007 404(3):353-63. [PubMed: 17521290]

[37]. Meusser B, Hirsch C, Jarosch E, Sommer T. ERAD: the long road to destruction. Nat Cell Biol Aug;2005 7(8):766-72. [PubMed: 16056268]

[38]. Lord JM, Roberts LM, Stirling CJ. Quality control: another player joins the ERAD cast. Curr Biol Dec 6;2005 15(23):R963-4. [PubMed: 16332527]

[39]. Urano F, Wang X, Bertolotti A, Zhang Y, Chung P, Harding HP, et al. Coupling of stress in the ER to activation of JNK protein kinases by transmembrane protein kinase IRE1. Science Jan 28;2000 287(5453):664-6. [PubMed: 10650002]

[40]. Yoneda T, Imaizumi K, Oono K, Yui D, Gomi F, Katayama T, et al. Activation of caspase-12, an endoplastic reticulum (ER) resident caspase, through tumor necrosis factor receptor-associated factor 2-dependent mechanism in response to the ER stress. J Biol Chem Apr 27;2001 276(17): 13935-40. [PubMed: 11278723]

[41]. Hacki J, Egger L, Monney L, Conus S, Rosse T, Fellay I, et al. Apoptotic crosstalk between the endoplasmic reticulum and mitochondria controlled by Bcl-2. Oncogene May 4;2000 19(19):228695. [PubMed: 10822379]

[42]. Hetz C, Bernasconi P, Fisher J, Lee AH, Bassik MC, Antonsson B, et al. Proapoptotic BAX and BAK modulate the unfolded protein response by a direct interaction with IRE1alpha. Science Apr 28;2006 312(5773):572-6. [PubMed: 16645094]

[43]. Haze K, Yoshida H, Yanagi H, Yura T, Mori K. Mammalian transcription factor ATF6 is synthesized as a transmembrane protein and activated by proteolysis in response to endoplasmic reticulum stress. Mol Biol Cell Nov;1999 10(11):3787-99. [PubMed: 10564271] 
[44]. Wang Y, Shen J, Arenzana N, Tirasophon W, Kaufman RJ, Prywes R. Activation of ATF6 and an ATF6 DNA binding site by the endoplasmic reticulum stress response. J Biol Chem Sep 1;2000 275(35):27013-20. [PubMed: 10856300]

[45]. Thuerauf DJ, Hoover H, Meller J, Hernandez J, Su L, Andrews C, et al. Sarco/endoplasmic reticulum calcium ATPase-2 expression is regulated by ATF6 during the endoplasmic reticulum stress response: intracellular signaling of calcium stress in a cardiac myocyte model system. J Biol Chem Dec 21;2001 276(51):48309-17. [PubMed: 11595740]

[46]. Rao RV, Peel A, Logvinova A, del Rio G, Hermel E, Yokota T, et al. Coupling endoplasmic reticulum stress to the cell death program: role of the ER chaperone GRP78. FEBS Lett Mar 13;2002 514(23):122-8. [PubMed: 11943137]

[47]. Shiu RP, Pouyssegur J, Pastan I. Glucose depletion accounts for the induction of two transformationsensitive membrane proteinsin Rous sarcoma virus-transformed chick embryo fibroblasts. Proc Natl Acad Sci U S A Sep;1977 74(9):3840-4. [PubMed: 198809]

[48]. Welch WJ, Garrels JI, Thomas GP, Lin JJ, Feramisco JR. Biochemical characterization of the mammalian stress proteins and identification of two stress proteins as glucose- and $\mathrm{Ca} 2+$-ionophoreregulated proteins. J Biol Chem Jun 10;1983 258(11):7102-11. [PubMed: 6406494]

[49]. Gorlach A, Klappa P, Kietzmann T. The endoplasmic reticulum: folding, calcium homeostasis, signaling, and redox control. Antioxid Redox Signal Sep-Oct;2006 8(910):1391-418. [PubMed: 16986999]

[50]. Paschen W. Endoplasmic reticulum dysfunction in brain pathology: critical role of protein synthesis. Curr Neurovasc Res Apr;2004 1(2):173-81. [PubMed: 16185192]

[51]. Hayashi T, Saito A, Okuno S, Ferrand-Drake M, Chan PH. Induction of GRP78 by ischemic preconditioning reduces endoplasmic reticulum stress and prevents delayed neuronal cell death. $\mathbf{J}$ Cereb Blood Flow Metab Aug;2003 23(8):949-61. [PubMed: 12902839]

[52]. Vikman P, Edvinsson L. Gene expression profiling in the human middle cerebral artery after cerebral ischemia. Eur J Neurol Dec;2006 13(12):1324-32. [PubMed: 17116215]

[53]. Bi M, Naczki C, Koritzinsky M, Fels D, Blais J, Hu N, et al. ER stress-regulated translation increases tolerance to extreme hypoxia and promotes tumor growth. Embo J Oct 5;2005 24(19):3470-81. [PubMed: 16148948]

[54]. Koumenis C. ER stress, hypoxia tolerance and tumor progression. Curr Mol Med Feb;2006 6(1): 55-69. [PubMed: 16472113]

[55]. Feldman DE, Chauhan V, Koong AC. The unfolded protein response: a novel component of the hypoxic stress response in tumors. Mol Cancer Res Nov;2005 3(11):597-605. [PubMed: 16317085]

[56]. Thuerauf DJ, Marcinko M, Gude N, Rubio M, Sussman MA, Glembotski CC. Activation of the unfolded protein response in infarcted mouse heart and hypoxic cultured cardiac myocytes. Circ Res Aug 4;2006 99(3):275-82. [PubMed: 16794188]

[57]. Qi X, Vallentin A, Churchill E, Mochly-Rosen D. deltaPKC participates in the endoplasmic reticulum stress-induced response in cultured cardiac myocytes and ischemic heart. J Mol Cell Cardiol Oct;2007 43(4):420-8. [PubMed: 17825316]

[58]. Azfer A, Niu J, Rogers LM, Adamski FM, Kolattukudy PE. Activation of endoplasmic reticulum stress response during the development of ischemic heart disease. Am J Physiol Heart Circ Physiol Sep;2006 291(3):H1411-20. [PubMed: 16617122]

[59]. Severino A, Campioni M, Straino S, Salloum FN, Schmidt N, Herbrand U, et al. Identification of protein disulfide isomerase as a cardiomyocyte survival factor in ischemic cardiomyopathy. $\mathrm{J}$ Am Coll Cardiol Sep 11;2007 50(11):1029-37. [PubMed: 17825711]

[60]. Terai K, Hiramoto Y, Masaki M, Sugiyama S, Kuroda T, Hori M, et al. AMP-activated protein kinase protects cardiomyocytes against hypoxic injury through attenuation of endoplasmic reticulum stress. Mol Cell Biol Nov;2005 25(21):9554-75. [PubMed: 16227605]

[61]. Szegezdi E, Duffy A, O’Mahoney ME, Logue SE, Mylotte LA, O’Brien T, et al. ER stress contributes to ischemia-induced cardiomyocyte apoptosis. Biochem Biophys Res Commun Nov 3;2006 349(4):1406-11. [PubMed: 16979584]

[62]. Martindale JJ, Fernandez R, Thuerauf D, Whittaker R, Gude N, Sussman MA, et al. Endoplasmic reticulum stress gene induction and protection from ischemia/reperfusion injury in the hearts of 
transgenic mice with a tamoxifen-regulated form of ATF6. Circ Res May 12;2006 98(9):1186-93. [PubMed: 16601230]

[63]. Shintani-Ishida K, Nakajima M, Uemura K, Yoshida K. Ischemic preconditioning protects cardiomyocytes against ischemic injury by inducing GRP78. Biochem Biophys Res Commun Jul 14;2006 345(4):1600-5. [PubMed: 16735028]

[64]. Zhang PL, Lun M, Teng J, Huang J, Blasick TM, Yin L, et al. Preinduced molecular chaperones in the endoplasmic reticulum protect cardiomyocytes from lethal injury. Ann Clin Lab Sci 2004 Autumn;34(4):449-57. [PubMed: 15648788]

[65]. Vitadello M, Penzo D, Petronilli V, Michieli G, Gomirato S, Menabo R, et al. Overexpression of the stress protein Grp94 reduces cardiomyocyte necrosis due to calcium overload and simulated ischemia. Faseb J May;2003 17(8):923-5. [PubMed: 12670879]

[66]. Takagi H, Matsui Y, Sadoshima J. The role of autophagy in mediating cell survival and death during ischemia and reperfusion in the heart. Antioxid Redox Signal Sep;2007 9(9):1373-81. [PubMed: 17627477]

[67]. Nickson P, Toth A, Erhardt P. PUMA is critical for neonatal cardiomyocyte apoptosis induced by endoplasmic reticulum stress. Cardiovasc Res Jan 1;2007 73(1):48-56. [PubMed: 17107669]

[68]. Toth A, Jeffers JR, Nickson P, Min JY, Morgan JP, Zambetti GP, et al. Targeted deletion of Puma attenuates cardiomyocyte death and improves cardiac function during ischemia-reperfusion. Am J Physiol Heart Circ Physiol Jul;2006 291(1):H52-60. [PubMed: 16399862]

[69]. Rutkowski DT, Arnold SM, Miller CN, Wu J, Li J, Gunnison KM, et al. Adaptation to ER stress is mediated by differential stabilities of prosurvival and pro-apoptotic mRNAs and proteins. PLoS Biol Nov;2006 4(11):e374. [PubMed: 17090218]

[70]. Okada K, Minamino T, Tsukamoto Y, Liao Y, Tsukamoto O, Takashima S, et al. Prolonged endoplasmic reticulum stress in hypertrophic and failing heart after aortic constriction: possible contribution of endoplasmic reticulum stress to cardiac myocyte apoptosis. Circulation Aug 10;2004 110(6):705-12. [PubMed: 15289376]

[71]. Hamada H, Suzuki M, Yuasa S, Mimura N, Shinozuka N, Takada Y, et al. Dilated cardiomyopathy caused by aberrant endoplasmic reticulum quality control in mutant KDEL receptor transgenic mice. Mol Cell Biol Sep;2004 24(18):8007-17. [PubMed: 15340063]

[72]. Barnes JA, Smoak IW. Glucose-regulated protein 78 (GRP78) is elevated in embryonic mouse heart and induced following hypoglycemic stress. Anat Embryol (Berl) Jul;2000 202(1):67-74. [PubMed: 10926097]

[73]. Mao C, Tai WC, Bai Y, Poizat C, Lee AS. In vivo regulation of Grp78/BiP transcription in the embryonic heart: role of the endoplasmic reticulum stress response element and GATA-4. J Biol Chem Mar 31;2006 281(13):8877-87. [PubMed: 16452489]

[74]. Masaki T, Yoshida M, Noguchi S. Targeted disruption of CRE-binding factor TREB5 gene leads to cellular necrosis in cardiac myocytes at the embryonic stage. Biochem Biophys Res Commun Aug 2;1999 261(2):350-6. [PubMed: 10425189] 

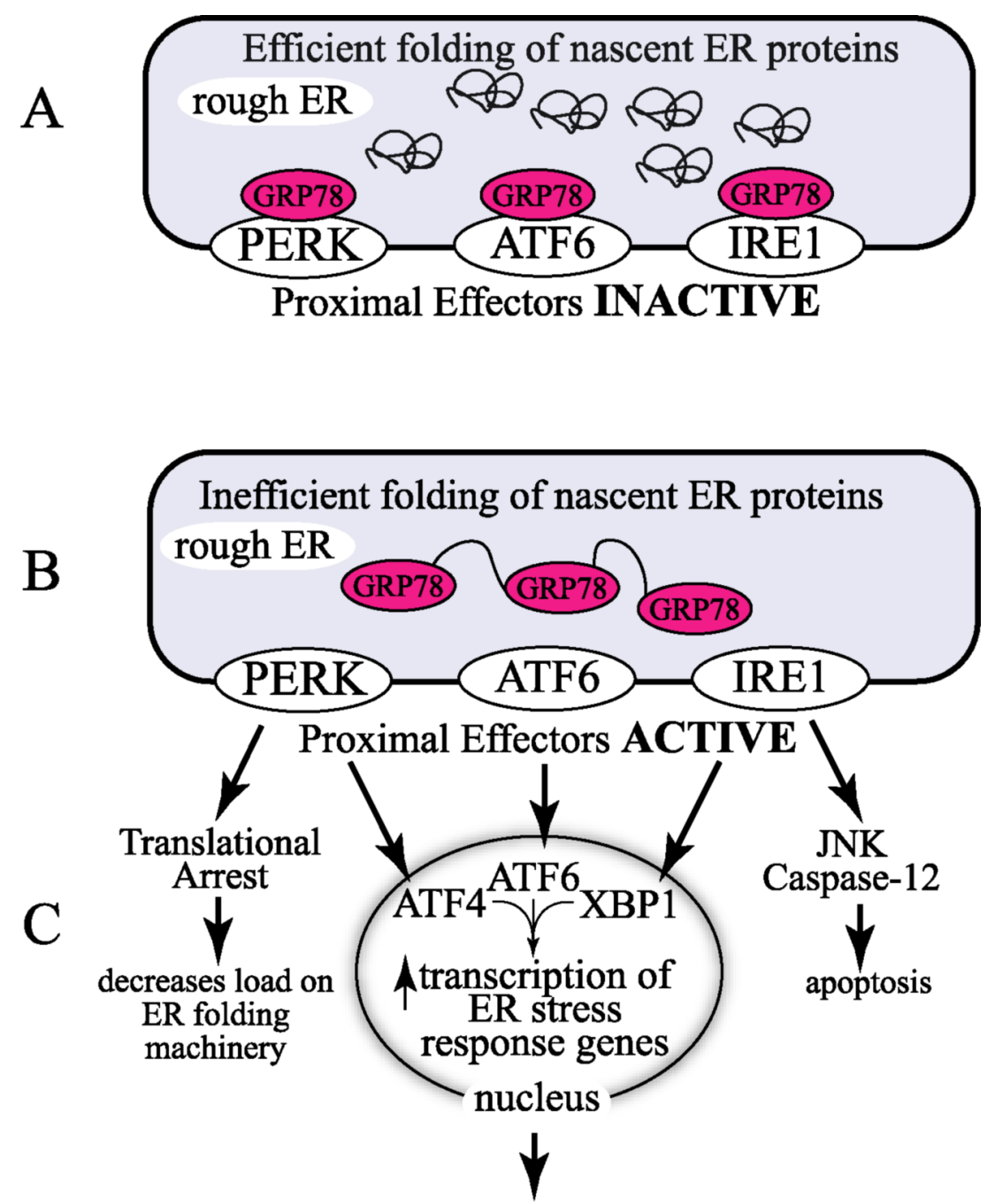

ER Stress Response Proteins Foster

\author{
Survival/Recovery \\ chaperones (e.g. GRP78) \\ disulfide isomerases (e.g. PDI)
}

D calcium binding proteins (e.g. calreticulin)

Apoptosis

death promoters (e.g. CHOP)

Figure 1.

The Unfolded Protein Response:

Panel A- Under non-stressed conditions, proteins that are synthesized in the rough ER are efficiently folded. The ER-resident molecular chaperone, glucose-regulated protein-78 (GRP78), is associated with the luminal domains of the 3 proximal effectors of the unfolded protein response (UPR), PKR-like ER kinase (PERK), inositol-required enzyme-1 (IRE-1) and activating transcription factor 6 (ATF6). Under these conditions, these 3 UPR effectors are inactive in terms of activating downstream effects of the UPR.

Panel B-Stresses that perturb the redox status of the ER lumen, alter ER calcium levels, or disrupt the ER protein glycostylation machinery, result in the accumulation of mis-folded, 
dysfunctional proteins in the ER lumen, which initiates ER stress. Upon ER stress, GRP78 translocates from the luminal domains of PERK, ATF6 and IRE-1 to the misfolded proteins in the ER lumen in an effort to assist in folding. Under these conditions, PERK, ATF6 and IRE-1 and ATF6 are activated.

Panel $\boldsymbol{C}$ - The PERK, ATF6 and IRE-1 branches of the UPR each mediate the transcriptional induction of ER stress response genes via the transcription factors, ATF4, ATF6 and XBP1, respectively. In addition, PERK can mediate global translational arrest by phosphorylation eIf $2 \alpha$, and IRE- 1 can mediate the activation of JNK and caspase-12. Translational arrest decreases the workload on the ER, allowing time for recovery; however, the mRNAs encoded by many ER stress response genes have evolved structural features that allow them to escape this translational arrest, which is important for the up-regulation of ER stress response proteins upon acute stress. The JNK and caspase- 12 branches of the UPR contribute to programmed cell death that takes place upon chronic ER stress. Many ER stress response genes encode ERtargeted chaperones, and other ER proteins that are designed to stabilize and/or re-establish an ER luminal environment that is suitable for nascent ER protein folding, facilitating cell survival and recovery from acute ER stress (Survival/Recovery). However, if the stress is not resolved, ER stress response genes induced upon chronic stress lead to apoptotic cell death

(Apoptosis). 